\title{
Interpretation of AIRS Data in Thin Cirrus Atmospheres Based on a Fast Radiative Transfer Model
}

\author{
Qing Yue, K. N. Liou, And S. C. Ou \\ Department of Atmospheric and Oceanic Sciences, University of California, Los Angeles, Los Angeles, California \\ B. H. KAHN \\ Jet Propulsion Laboratory, California Institute of Technology, Pasadena, California \\ P. YANG \\ Department of Atmospheric Sciences, Texas A\&M University, College Station, Texas \\ G. G. MACE \\ Department of Meteorology, University of Utah, Salt Lake City, Utah
}

(Manuscript received 24 January 2006, in final form 26 December 2006)

\begin{abstract}
A thin cirrus cloud thermal infrared radiative transfer model has been developed for application to cloudy satellite data assimilation. This radiation model was constructed by combining the Optical Path Transmittance (OPTRAN) model, developed for the speedy calculation of transmittances in clear atmospheres, and a thin cirrus cloud parameterization using a number of observed ice crystal size and shape distributions. Numerical simulations show that cirrus cloudy radiances in the $800-1130-\mathrm{cm}^{-1}$ thermal infrared window are sufficiently sensitive to variations in cirrus optical depth and ice crystal size as well as in ice crystal shape if appropriate habit distribution models are selected a priori for analysis. The parameterization model has been applied to the Atmospheric Infrared Sounder (AIRS) on board the Aqua satellite to interpret clear and thin cirrus spectra observed in the thermal infrared window. Five clear and 29 thin cirrus cases at nighttime over and near the Atmospheric Radiation Measurement program (ARM) tropical western Pacific (TWP) Manus Island and Nauru Island sites have been chosen for this study. A $\chi^{2}$-minimization program was employed to infer the cirrus optical depth and ice crystal size and shape from the observed AIRS spectra. Independent validation shows that the AIRS-inferred cloud parameters are consistent with those determined from collocated ground-based millimeter-wave cloud radar measurements. The coupled thin cirrus radiative transfer parameterization and OPTRAN, if combined with a reliable thin cirrus detection scheme, can be effectively used to enhance the AIRS data volume for data assimilation in numerical weather prediction models.
\end{abstract}

\section{Introduction}

Satellite data assimilation in numerical weather prediction models requires an efficient and accurate radiative transfer model for the computation of radiances and Jacobians. Present thermal infrared radiative transfer models for satellite data assimilation have been de-

Corresponding author address: Ms. Qing Yue, Department of Atmospheric and Oceanic Sciences, University of California, Los Angeles, 405 Hilgard Ave., Los Angeles, CA 90095-1565.

E-mail: qingyue@atmos.ucla.edu veloped primarily for clear conditions (i.e., pure absorbing atmospheres). However, many studies have found that a great majority of satellite observations is "contaminated" by clouds. For example, Saunders (2000) showed that only $6.5 \%$ of the High Resolution Infrared Radiometer Sounder (HIRS) footprints were clear based on the analysis of the collocated HIRS 17$\mathrm{km}$ and the Advanced Very High Resolution Radiometer Global Area Coverage data. Using Atmospheric Infrared Sounder (AIRS; Aumann et al. 2003) simulated data, it was reported that less than $1 \%$ of the AIRS-observed fields of view were found to be cloud

DOI: $10.1175 / 2007 J A S 2043.1$

(C) 2007 American Meteorological Society 
free at the instrumental noise level (Chahine et al. 2006). Of the large number of cloud-contaminated satellite observations, Wylie and Menzel (1999) reported that $34 \%$ of HIRS observations between $65^{\circ} \mathrm{S}$ and $65^{\circ} \mathrm{N}$ contained high-level clouds (both semitransparent and opaque) above $6 \mathrm{~km}$. In addition, Wang et al. (1996) illustrated that $50 \%-70 \%$ of the Limb-sounding Stratospheric Aerosol and Gas Experiment data were contaminated by cirrus clouds.

Satellite-derived cloud climatology shows that cirrus clouds regularly cover about $20 \%-30 \%$ of the globe (Liou 1986). In particular, Wylie et al. (2005) reported that optically thin cirrus clouds with visible optical depths less than 1.4 were found in $20 \%$ of the HIRS data from 1979 to 2001 . The effect of cirrus clouds on the energy balance of the earth-atmosphere system is a topic of critical importance because on the one hand, they affect solar radiation, referred to as the albedo effect, and on the other hand, they trap a significant amount of thermal infrared radiation emitted from the atmosphere below and the surface, referred to as the greenhouse effect. The competition between the two effects determines the gain and loss of radiative energy and hence the warming and cooling of the atmosphere. It is clear that thin cirrus clouds play an important role in global climate study. Moreover, in view of the fact that many advanced infrared and microwave sensors have been and will be deployed in space in the near future and that there appears to be a need for the incorporation of thin cirrus cloudy radiance data in numerical weather prediction models, it is important to develop a radiative transfer model for infrared satellite data simulation that can be effectively applied to thin cirrus cloudy atmosphere where upwelling radiances only marginally deviates from clear radiances. In our study, we are particularly interested in thin cirrus clouds with optical depths less than about 1.0.

We have developed an efficient radiative transfer model by combining the Optical Path Transmittance (OPTRAN) program (McMillin et al. 1995b; Kleespies et al. 2004) for the speedy computation of clear-column transmittances in numerical weather prediction models, and a thin cirrus radiative transfer parameterization based on prescribed size and habit distribution models and the associated scattering and absorption properties. We use this model to simulate infrared spectral radiances, and apply it to the AIRS data to generate clear and thin cirrus cloud brightness temperature (BT) spectra. Cirrus optical depth and cloud microphysical properties, including size and habit factors, have been inferred by a $\chi^{2}$-minimization program involving differences between the modeled and measured AIRS BT spectra. Moreover, we compare these inferred values to the independently derived cirrus optical depth and ice crystal size from collocated and coincident groundbased Department of Energy's (DOE's) Atmospheric Radiation Measurement (ARM) program millimeterwave cloud radar (MMCR) retrievals. We have also carried out numerical experiments to study the sensitivity of the BT spectra to cirrus optical depth and ice crystal size and habit.

This paper is organized as follows. Section 2 presents the infrared radiative transfer model along with a thin cirrus parameterization. Also included are discussions of the database for ice crystal size and habit distributions, the single-scattering properties for nonspherical ice crystals, and the methodology for computing the bulk properties of cirrus clouds. Section 3 describes the calculation of clear and thin cirrus cloudy radiances, and the $\chi^{2}$-minimization method for inferring optical depth and ice crystal size and habit. In section 4 we show results of the sensitivity study, apply our methodology to three AIRS data granules over the ARM tropical western Pacific (TWP) sites, and compare the inferred cloud properties with the ground-based MMCR retrievals. Finally, a summary is given in section 5 .

\section{A thin cirrus radiative transfer parameterization}

\section{a. Radiative transfer model}

Based on the principle of radiative transfer, the upwelling radiance $I_{\nu}$ at the top of the atmosphere (TOA) in cirrus cloudy atmospheres is contributed by the radiance transmitted through the cloud from the atmosphere and surface below and the radiance emitted from the cloud. Thus, we have the following linear equation (Ou et al. 1993):

$$
I_{\nu}=I_{0}\left(1-\varepsilon_{\nu}\right)+\varepsilon_{\nu} B_{\nu}\left(T_{c}\right),
$$

where the two terms on the right denote the transmission and emission contributions, respectively, and $I_{0}$ denotes the upwelling thermal infrared radiances reaching the cloud base. Since tropical cirrus clouds locate in the upper troposphere above which temperature is cold and the water vapor amount is low, the contribution of emissions from water vapor above cirrus is small compared to the transmission through the cloud and the emission from the cloud itself, and can be neglected. Thus, $I_{0}$ is simply referred to as the clear radiance in this study. Here $B_{\nu}\left(T_{c}\right)$ is the cloud Planck radiance at a wavenumber $\nu$, and the cloud temperature is denoted by $T_{c}$. The cloud emittance is denoted by $\varepsilon_{v}$, which under local thermodynamic equilibrium can be defined 
for remote sensing application (Minnis et al. 1998) as follows:

$$
\varepsilon_{\nu}=1-\exp \left[-\left(1-\omega_{\nu}\right) \tau_{\mathrm{IR}} / \mu\right] \approx-\left(1-\omega_{\nu}\right) \tau_{\mathrm{IR}} / \mu,
$$

where $\mu$ is the cosine of the viewing angle, $\tau_{\mathrm{IR}}$ is the infrared optical depth of a given cloud layer, $\omega_{\nu}$ is the single-scattering albedo, and $\left(1-\omega_{\nu}\right) \tau_{\mathrm{IR}}$ is defined as the spectrally dependent cloud absorption optical depth. Equation (2) is applicable to cirrus clouds with optical depths approaching 0 .

To evaluate $\tau_{\mathrm{IR}}$ in Eq. (2), a relationship between visible and infrared optical depths is needed. Because the typical ice particle size is much larger than the visible wavelength, the mean extinction efficiency of an ensemble of ice crystals at a visible wavelength is approximately given by the geometric-optics asymptotic value of 2 . The infrared optical depth can then be approximated by (Minnis et al. 1998)

$$
\tau_{\mathrm{IR}} \approx \frac{\left\langle Q_{\mathrm{ext}, \mathrm{IR}}\right\rangle}{2} \tau,
$$

where $\left\langle Q_{\text {ext,IR }}\right\rangle$ is the mean extinction efficiency at an infrared wavelength to be defined in section $2 \mathrm{c}$, and $\tau$ is the cirrus cloud optical depth at a visible wavelength (e.g., $0.65 \mu \mathrm{m}$ ).

\section{b. Ice crystal size distribution and habit distribution models}

To build size distribution (SD) and habit distribution (HD) models for computing radiances in various thin cirrus conditions, we have acquired nine size distributions based on the microphysics measurements from the Central Equatorial Pacific Experiment (CEPEX) that was conducted during March and April 1993, as given in Rolland et al. (2000) and McFarquhar and Heymsfield (1996). The microphysical measurements were made by the Aeromet Learjet between $20^{\circ} \mathrm{S}$ and $2^{\circ} \mathrm{N}$ latitude and between $165^{\circ} \mathrm{E}$ and $170^{\circ} \mathrm{W}$ longitude, with operations centered at Nadi, Fiji.

We used the microphysical observations corresponding to three anvils that were carried out on 4 April, 1 April, and 17 March 1993. On 4 April, the Learjet flew through a cumulonimbus complex northeast of Fiji between 2150 and 0207 UTC. On 1 April, the airborne probes sampled a well-defined cirrus anvil associated with a dissipating nocturnal thunderstorm north of Nadi. The cirrus sampled on 17 March was the outflow of a much deeper convective disturbance. The microphysical data from these flights were expected to be representative of the ice crystal size distributions typical of tropical cirrus anvil and convective clouds. Airborne in situ instruments included the 2D cloud probe (2D-C), which sampled ice crystals with maximum dimension from 30 to $1800 \mu \mathrm{m}$ with a resolution of 30 and $40 \mu \mathrm{m}$ in the $y$ and $x$ directions, respectively, and the video ice particle sampler (VIPS), which measured smaller ice crystals with a low detection limit of approximately $5-10 \mu \mathrm{m}$.

To characterize the ice crystal SD, a mean effective size $D_{e}$ is defined as 1.5 times the ratio of ensemble particle volume and the particle projected area as follows (Foot 1988; Francis et al. 1994; Wyser and Yang 1998):

$$
D_{e l, k}=\frac{3}{2} \frac{\int_{L_{\min k}}^{L_{\max k}}\left[\sum_{i=1}^{7} f_{i, l}(L) V_{i}(L)\right] n_{k}(L) d L}{\int_{L_{\min k}}^{L_{\max k}}\left[\sum_{i=1}^{7} f_{i, l}(L) A_{i}(L)\right] n_{k}(L) d L}=\frac{3}{2} \frac{V_{l, k}}{A_{l, k}} \cdot \begin{aligned}
& l=1, \ldots, 11 \\
& k=1, \ldots, 9,
\end{aligned}
$$

where $l$ and $k$ are indices for $\mathrm{HD}$ and SD, ranging from 1 to 11 and 1 to 9 , respectively. Here $V_{i}(L)$ and $A_{i}(L)$ are the volume and projected area of an ice particle with a maximum dimension $L$ for the $i$ th habit, respectively; $f_{i, l}(L)$ is the fraction of the $i$ th habit in the $l$ th $\mathrm{HD} ; n_{k}(L) d L$ is the number density of ice crystals in the size interval $(L, L+d L)$ for the $k$ th SD; $L_{\min k}$ and $L_{\max k}$ are the minimum and maximum $L$ for the $k$ th $\mathrm{SD}$, respectively; and $V_{l, k}$ and $A_{l, k}$ are the total volume and projected area for the set of the $l$ th HD and the $k$ th $\mathrm{SD}$, respectively. There is only one unique $D_{e l, k}$ value for a given set of the $l$ th HD and the $k$ th SD (hereafter
$D_{e l, k}$ will be simply referred to as $\left.D_{e}\right)$. As shown in $\mathrm{Fu}$ and Liou (1993) for parameterization of the broadband radiative properties of ice clouds, and in Rolland et al. (2000) for the satellite remote sensing of cirrus clouds, the $D_{e}$ is the key parameter representing the scattering and absorption properties of a spectrum of sizes and shapes.

Figure 1a shows the four composite ice crystal SDs (CEPEX01-04) based on an averaging procedure such that the associated ice water content (IWC) is defined in the intervals of four bins: $10^{-4}$ to $10^{-3}, 10^{-3}$ to $10^{-2}$, $10^{-2}$ to $10^{-1}$, and $10^{-1}$ to $0.32 \mathrm{~g} \mathrm{~m}^{-3}$. Their mean ef- 


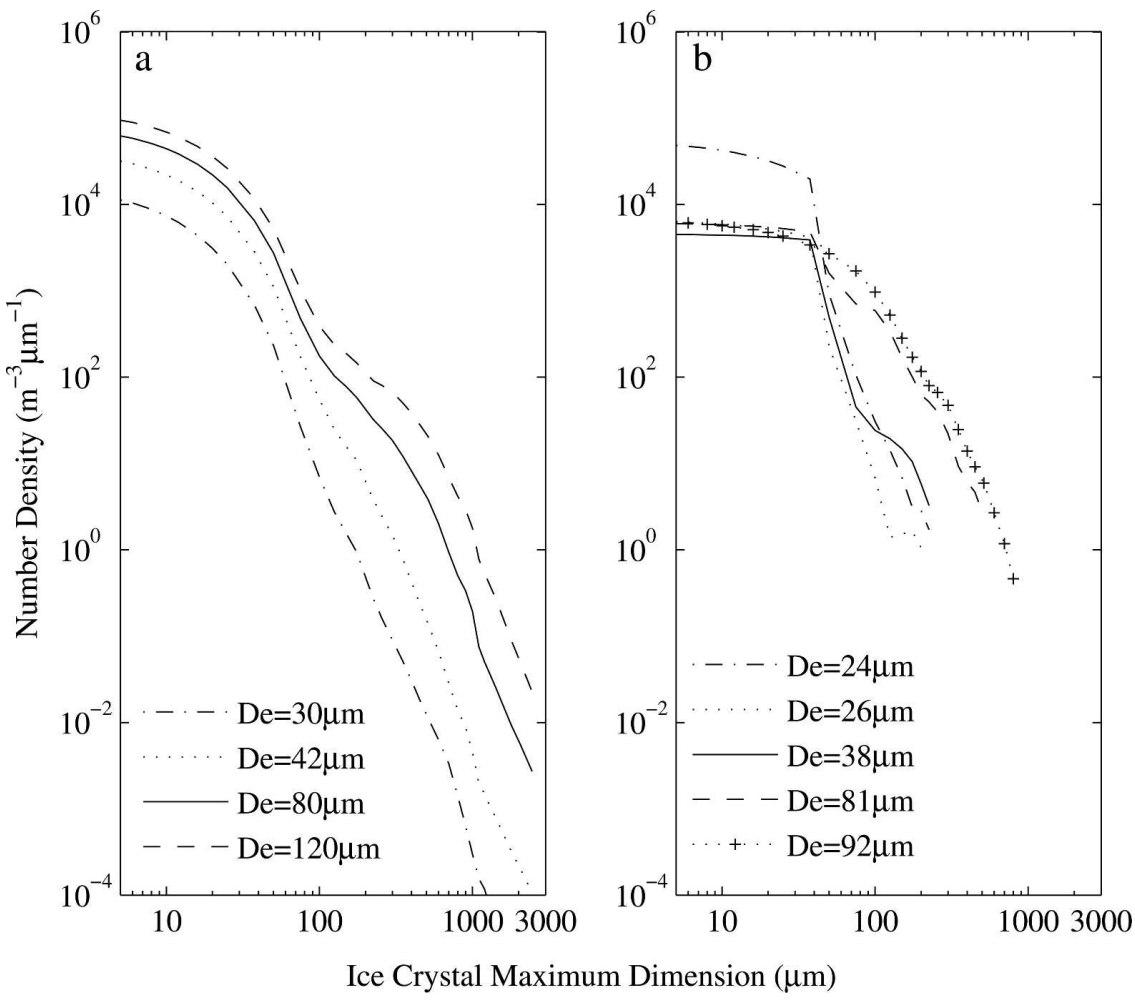

FIG. 1. Nine CEPEX SD functions: (a) four composite ice crystal SDs (CEPEX01-04) with the mean effective sizes of $30,42,80$, and $120 \mu \mathrm{m}$ and the associated ice water content ranges of $10^{-4}$ to $10^{-3}, 10^{-3}$ to $10^{-2}, 10^{-2}$ to $10^{-1}$, and $10^{-1}$ to $0.32 \mathrm{~g} \mathrm{~m}^{-3}$, respectively; (b) five ice crystal SDs (CEPEX05-09) from in situ measurements taken at 2250, 2341, 2342, 2347, and 2348 UTC on 4 Apr 1993 with the mean effective sizes of $24,26,38,81,92 \mu \mathrm{m}$, respectively. The mean effective size was obtained by assuming $100 \%$ solid hexagonal columns (HD11).

fective sizes are 30, 42, 80, and $120 \mu \mathrm{m}$, respectively, following Eq. (4) and assuming 100\% solid hexagonal columns. These composite SDs are obtained from thousands of 2D-C-observed data by averaging all spectra within IWC intervals. Since the $2 \mathrm{D}-\mathrm{C}$ data are skewed toward ice crystals larger than about 90-100 $\mu \mathrm{m}$, especially at aircraft flight speeds $\left(\sim 200 \mathrm{~m} \mathrm{~s}^{-1}\right)$, the SDs for ice crystals smaller than $90 \mu \mathrm{m}$ were obtained from a parameterization scheme developed by McFarquhar and Heymsfield (1997). A slightly bimodal structure is noted for all the SDs. The "fine" mode, consisting of small particles, is located near the low end of the size spectrum, while the "coarse" mode is around 200-600 $\mu \mathrm{m}$. This bimodal structure in SD is characteristic based on analyses of the CEPEX data, particularly when a significant number of ice crystals were present (McFarquhar and Heymsfield 1996). Both the numbers of large and small ice crystals increase as IWC increases. However, more large ice crystals were commonly found at higher IWCs, consistent with the fact that large ice crystals contribute more significantly to the amount of IWC (McFarquhar and Heymsfield 1997).

Figure 1b shows the other five SDs (CEPEX05-09), which were obtained at 2250, 2341, 2342, 2347, and 2348 UTC on 4 April 1993. The mean effective sizes of the five SDs are 24, 26, 38, 81, $92 \mu \mathrm{m}$, respectively, assuming $100 \%$ solid hexagonal columns. Data from the VIPS measurement were included to account for ice crystals with maximum dimensions less than about $120 \mu \mathrm{m}$. For ice particles larger than $120 \mu \mathrm{m}$, the SDs were obtained from 2D-C measurements. This particular date was chosen because the measurements from VIPS for the largest sizes and those from 2D-C for smallest sizes agreed better than the 1 April case. Note that VIPS data were not available for the 17 March case (McFarquhar and Heymsfield 1996). Except for the two SDs with the largest mean effective sizes of 81 and $92 \mu \mathrm{m}$, the coarse mode is not as obvious as that appears in the averaged SDs. The SD with the smallest mean effective size of $24 \mu \mathrm{m}$ has the largest portion of ice crystals smaller than $40 \mu \mathrm{m}$ but a limited number of large crys- 
TABLE 1. Eleven habit distribution functions based on in situ data collected during CEPEX, TRMM, CRYSTAL-FACE, and the prescriptions by various researchers. The terms HC, SC, P, BR, A, and D in this table denote hollow column, solid column, plate, bullet rosette, aggregate, and droxtal, respectively.

\begin{tabular}{|c|c|c|c|}
\hline Number & Composition & Field campaign & Reference \\
\hline HD1 & $99.0 \% \mathrm{HC}, 0.4 \% \mathrm{P}, 0.6 \% \mathrm{BR}$ & CEPEX & Rolland et al. (2000) \\
\hline HD2 & $64.5 \% \mathrm{HC}, 30.5 \% \mathrm{P}, 5.0 \% \mathrm{BR}$ & CEPEX & Rolland et al. (2000) \\
\hline HD3 & $58.4 \% \mathrm{HC}, 21.5 \% \mathrm{P}, 8.6 \% \mathrm{BR}, 11.5 \% \mathrm{~A}$ & CEPEX & Rolland et al. (2000) \\
\hline HD4 & $50.7 \% \mathrm{HC}, 16.3 \% \mathrm{P}, 22.9 \% \mathrm{BR}, 10.1 \% \mathrm{~A}$ & CEPEX & Rolland et al. (2000) \\
\hline HD5 & $57.9 \% \mathrm{HC}, 26.7 \% \mathrm{P}, 6.3 \% \mathrm{BR}, 9.1 \% \mathrm{~A}$ & CEPEX & Rolland et al. (2000) \\
\hline HD6 & $58.6 \% \mathrm{HC}, 8.4 \% \mathrm{P}, 20.0 \% \mathrm{BR}, 13.0 \% \mathrm{~A}$ & CEPEX & Rolland et al. (2000) \\
\hline HD7 & $33.7 \%$ SC, $24.7 \%$ BR, $41.6 \%$ A & CEPEX & McFarquhar et al. (1999) \\
\hline HD8 & $\begin{array}{l}L<60 \mu \mathrm{m}, 100 \% \text { D } 60 \mu \mathrm{m}<L<1000 \mu \mathrm{m}, \\
50 \% \mathrm{SC}, 35 \% \text { P, } 15 \% \text { BR } 1000 \mu \mathrm{m}<L<2000 \mu \mathrm{m}, \\
45 \% \mathrm{SC}, 45 \% \mathrm{HC}, 10 \% \text { A } L>2000 \mu \mathrm{m}, 97 \% \mathrm{BR}, 3 \% \mathrm{~A}\end{array}$ & TRMM CRYSTAL-FACE & Baum et al. (2005) \\
\hline HD9 & $L<60 \mu \mathrm{m}, 100 \% \mathrm{D} L>60 \mu \mathrm{m}, 100 \% \mathrm{HC}$ & & $\begin{array}{l}\text { Yang et al. (2000), } \\
\text { Zhang et al. (2004), } \\
\text { Macke et al. (1996) }\end{array}$ \\
\hline HD10 & $100 \% \mathrm{HC}$ & & Macke et al. (1996) \\
\hline HD11 & $100 \% \mathrm{SC}$ & & Baum et al. (2005) \\
\hline
\end{tabular}

tals. Although small ice crystals are less important in determining IWC, they contribute much more significantly to the ice crystal scattering properties. For example, McFarquhar and Heymsfield (1996) found that ice crystals smaller than $40 \mu \mathrm{m}$ contribute up to $40 \%$ to cross-sectional area based on analysis of the 1 April and 4 April data, whereas their contribution to IWC is less than $20 \%$ in these two cases.

On the basis of a number of observations depicted in Table 1, we have established 11 HDs for tropical cirrus clouds in association with our study. The first six (HD16) were complied based on the analysis of in situ airborne observations during CEPEX (Rolland et al. 2000). In their study the existence of small ice crystals near cloud top was recognized. One measured CEPEX HD (HD7) was taken from the 2D-C data presented in McFarquhar et al. (1999) for the 4 April case. They found that the most predominant crystal habit on this particular date was polycrystals, which, in our study, are considered as aggregates. Yang et al. (2000) and Zhang et al. (2004) incorporated the droxtal shape in their HD model to represent small ice crystals observed at temperature below $-35^{\circ} \mathrm{C}$. Macke et al. (1996) showed that light scattering from hollow columns is representative of the scattering from most columnlike particles, including hollow columns, solid bullets, and hollow bullets. In our study, the mixture of droxtals and hollow columns is denoted as HD9, while the case involving $100 \%$ hollow columns is denoted as HD10. The case HD11 contains $100 \%$ solid columns. In a comprehensive study of ice crystal SDs for remote sensing application, Baum et al. (2005) found that the BT computed from HD11 tends to agree more closely with the observed tropical BT data, especially when small ice par- ticles are predominant, a common feature in thin cirrus clouds.

The HD and SD models in the present study were determined based on tropical data. Because midlatitude cirrus clouds are formed by different mechanisms and under different environmental conditions, their microphysical properties could be quite different from those in the Tropics. Thus, it would appear that separate HDs and SDs should be constructed for midlatitude cirrus clouds for future remote sensing study.

\section{c. Single-scattering properties for cirrus clouds}

Following Yang et al. (2000, 2003, 2005) and Zhang et al. (2004), we have considered seven ice crystal habits including droxtals, spheroids, plates, solid and hollow columns, bullet rosettes, and aggregates. For each habit, a separate library of the microphysical properties was developed, including maximum dimension, volume, projected area, and the single-scattering properties (single-scattering albedo, extinction efficiency, and asymmetry factor) for the spectral range between 3 and $100 \mu \mathrm{m}$. Moreover, 45 ice crystal size bins with a maximum dimension varying from 2 to $10000 \mu \mathrm{m}$ were used to account for SDs. For the purpose of computational efficiency, we used a fourth-order polynomial interpolation method to obtain the single-scattering properties of each ice crystal habit and size at the AIRS channel wavelengths. The bulk single-scattering properties of cirrus clouds used in radiative transfer simulations were subsequently obtained by integrating the singlescattering properties of individual ice crystals over a given set of SD and HD. Thus, the wavenumberdependent bulk single-scattering property is determined as follows: 


$$
\left\langle\zeta_{l, k}(\nu)\right\rangle=\frac{\int_{L_{\min k}}^{L_{\max k}}\left[\sum_{i=1}^{7} f_{i, l}(L) \zeta_{i}(L, \nu)\right] n_{k}(L) d L}{\int_{L_{\min k}}^{L_{\max k}}\left[\sum_{i=1}^{7} f_{i, l}(L)\right] n_{k}(L) d L} \quad \begin{gathered}
l=1, \ldots, 11 \\
k=1, \ldots, 9
\end{gathered},
$$

where $\zeta$ can be single-scattering albedo $\omega$, asymmetry factor $g$, or extinction efficiency $Q_{\text {ext }} ; \zeta_{i}(L, \nu)$ is defined as a function of maximum dimension $L$ and wavenumber $\nu$ for the $i$ th ice crystal habit. Here $\left\langle\zeta_{l, k}(\nu)\right\rangle$ denotes the bulk single-scattering property at wavenumber $\nu$ for a combination of the $l$ th HD and $k$ th SD. Subscripts $l$ and $k$ will be omitted for simplicity. Only $\langle\omega(\nu)\rangle$ and $\left\langle Q_{\text {ext }}(\nu)\right\rangle$ were used in the present thermal infrared radiative transfer model for thin cirrus.

\section{Interpretation of clear and cloudy spectra}

\section{a. Computation of clear radiance using OPTRAN}

The computationally efficient, parameterized transmittance code referred to as OPTRAN was developed by the scientists at the National Oceanic and Atmospheric Administration (NOAA; McMillin et al. 1995a) for use in satellite data assimilation in association with NWP modeling. The OPTRAN model incorporates a number of methodologies described in a series of papers since the 1970s. These advances include the rapid computation of atmospheric transmittance for constant-mixing-ratio gases at nadir view (McMillin and Fleming 1976), for different zenith angles (Fleming and McMillin 1977), and for gases with variable mixing ratios (McMillin et al. 1979). More recently, Kleespies et al. (2004) reported improvements for the OPTRAN code and an implementation that has been achieved for operational use. The most distinct approach in OPTRAN is the reversal of the usual roles of the pressure and absorber amount. The advantages of this performance include that 1) pressure is available for use as a predictor together with water vapor, ozone, and other gaseous components; 2) an arbitrary pressure profile is permitted in the calculation; and 3) the zenith angle is implicitly included in the absorber profile and explicit treatment is not necessary. In this approach, transmittance is computed through a recurrence procedure in which only simple calculations are involved.

The OPTRAN method has been applied to a number of instruments by Kleespies et al. (2004) who have tested the OPTRAN's accuracy by comparing with the calculation from a line-by-line radiative transfer model (Clough et al. 1992). Differences between the two in terms of brightness temperature were less than $0.2 \mathrm{~K}$ over the infrared spectrum. OPTRAN has also been utilized for the calculation of transmittances of the clear atmosphere for $\sim 600$ AIRS channels that are dominated by water vapor absorption (Strow et al. 2003).

In the present thin cirrus radiative transfer parameterization, OPTRAN is used to generate clear radiances $I_{0}$ in Eq. (1). The cloudy radiance $I_{\nu}$ can be obtained following Eqs. (1)-(3). The present simulations have been carried out for the thermal window from 800 to $1130 \mathrm{~cm}^{-1}$.

\section{b. Computation of thin cirrus radiance}

The atmospheric profiles used for radiance calculations are adopted from the AIRS level 2 Support Retrieval product datasets, including temperature, water vapor, and ozone, which are reported on 100 pressure levels from 1100 to $0.016 \mathrm{hPa}$. The surface skin temperature, surface pressure, and the index of the last physically meaningful profile level above the mean surface are utilized to determine the surface emission and the number of actual pressure levels above the surface. It is necessary to check this index in the calculation and extrapolate in the log (pressure) domain to obtain the surface value of water vapor and ozone (Olsen 2003). The satellite viewing angle is taken from the AIRS viewing geometry given in the AIRS full swath data fields. The spectral IR surface emissivity and bidirectional surface reflectivity are adopted from the AIRS level 2 standard retrieval product and given in order of increasing frequency. Manus Island cases were analyzed using version 3 (Olsen 2003) of the AIRS retrievals, while Nauru Island cases used version 4 (Olsen 2005). The selection of these cases will be discussed in section 4b. Employing all the aforementioned AIRS variables, clear radiances can be computed from OPTRAN.

The bulk single-scattering properties for clouds were calculated according to Eq. (5), and the cloud-top temperature was extracted from the AIRS level 2 standard product in which it was given within a pixel. Using the relationship between $\tau_{\text {IR }}$ and $\tau$ [Eq. (3)], the cloud emittance $\varepsilon_{\nu}$ is computed based on Eq. (2). The cloudy radiance is then evaluated following Eq. (1), where the clear radiance is obtained from OPTRAN. The simulated BT spectrum, which is converted from the cloudy radiance spectrum, is a function of $\tau, D_{e}$, and HD models. Using the aforementioned radiative transfer param- 
eterization, we have constructed look-up tables, which contain the simulated BT spectra in terms of these three parameters. The look-up tables are applied to a minimization method to search for the optimal combination of cirrus parameters that are associated with the minimum residual.

Many efforts have been devoted to the validation of AIRS products (Fetzer 2006). By comparing the observations of AIRS and the airborne Scanning HighResolution Interferometer throughout the infrared spectrum, Tobin et al. (2006) showed that the absolute values of mean BT differences were found to be less than $0.2 \mathrm{~K}$ for most channels. The AIRS sounding accuracy, in terms of RMS differences between AIRS retrieval and radiosonde, is: $1 \mathrm{~K}$ per $1 \mathrm{~km}$ layers for temperature and $15 \%$ per $2 \mathrm{~km}$ layers for water vapor (Divakarla et al. 2006). Kahn et al. (2006, manuscript submitted to J. Geophys. Res.) found that AIRSmeasured cloud-top heights statistically agree with MMCR and Micropulse lidar (MPL) measurements at ARM TWP sites and for cases associated with thin cirrus. Uncertainty in the cloud-top height is from -1.1 to $2.1 \mathrm{~km}$ on average.

c. Determination of cirrus optical depth and particle size using a $\chi^{2}$-minimization method

For each observed spectrum, a total of 9900 modeled spectra are calculated. These correspond to combinations of 9 CEPEX size distributions, 11 tropical cirrus habit distributions based on tropical measurements, and 100 visible cirrus optical depths varying from 0.01 to 1.0 inputted to the cloudy radiative transfer model. Within the $800-1130 \mathrm{~cm}^{-1}$ thermal window, we select 14 "clean" subbands for their minimal water vapor absorption effect. They cover 220 AIRS channels and their starting and ending wavenumbers are given in Table 2. These subbands have also been used in the Atmospheric Emitted Radiance Interferometer (AERI) analysis (DeSlover et al. 1999). Not all AERI subbands were used in our simulation. Only those covering more than 10 AIRS channels were adopted for obtaining statistically meaningful average BTs. Then a mean BT is calculated for each subband and is denoted as $\mathrm{BT}_{j}(\mathrm{Model})$, where the index $j$ ranges from 1 to 14 , corresponding to the 14 subbands selected. As a result, a total of 9900 subband $\mathrm{BT}_{j}$ (Model) spectra are computed. For each observed AIRS BT spectrum, we also

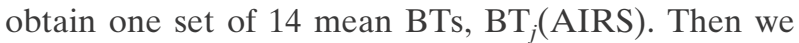
define a parameter $\chi^{2}$ as the sum of squared differences between $\mathrm{BT}_{j}\left(\right.$ Model) and $\mathrm{BT}_{j}(\mathrm{AIRS})$ :

$$
\chi^{2}=\sum_{j=1}^{14}\left[\mathrm{BT}_{j}(\text { Model })-\mathrm{BT}_{j}(\mathrm{AIRS})\right]^{2},
$$

TABLE 2. Clean subbands used in the determination of optical depth, ice crystal size, and habit function based on a minimization method and the numbers of AIRS channels covered by each subband.

\begin{tabular}{cccc}
\hline \hline Window & Start $\left(\mathrm{cm}^{-1}\right)$ & End $\left(\mathrm{cm}^{-1}\right)$ & $\begin{array}{c}\text { Number of } \\
\text { channels }\end{array}$ \\
\hline 1 & 809.061 & 812.919 & 10 \\
2 & 815.330 & 824.491 & 23 \\
3 & 828.348 & 834.617 & 15 \\
4 & 842.814 & 848.118 & 12 \\
5 & 860.172 & 864.030 & 11 \\
6 & 872.227 & 877.531 & 16 \\
7 & 891.996 & 895.853 & 11 \\
8 & 898.264 & 905.497 & 15 \\
9 & 929.606 & 939.731 & 26 \\
10 & 959.983 & 964.323 & 10 \\
11 & 985.056 & 998.075 & 30 \\
12 & 1076.670 & 1084.867 & 15 \\
13 & 1092.100 & 1098.850 & 12 \\
14 & 1124.406 & 1132.603 & 14 \\
\hline
\end{tabular}

where $\chi^{2}$ varies with different SD, HD, and $\tau$. Note that the $\chi^{2}$ defined above is not related to the standard statistical $\chi^{2}$ test. We search for the minimum $\chi^{2}$ to determine $D_{e}$, HD, and $\tau$ corresponding to the best-fit spectrum.

The search method may fail if the curve of $\chi^{2}$ with respect to one of the three parameters is flat, indicating that there is no constraint on this parameter. For this reason, we carefully examined the $\chi^{2}$ functions in reference to the three parameters. Figure 2 shows an example of the $\chi^{2}$ patterns with respect to SD, HD, and $\tau$. We found that none of the curves displays flatness, illustrating that the minimization method has constraint on all three parameters. In particular, $\chi^{2}-\mathrm{SD}$ and $\chi^{2}-\tau$ shown in Figs. 2a,c reveal a more tightly constraint of $\chi^{2}$ on SD and $\tau$. The $\chi^{2}-$ HD curve in Fig. $2 b$ does not show a systematic pattern because of the arbitrary order of HDs in Table 1.

\section{Results and discussions}

\section{a. Sensitivity study}

We used the standard tropical atmospheric profile (McClatchey et al. 1972) to investigate the sensitivity of thermal IR window BT spectra to optical depth and mean effective size that are determined by both SD and HD functions. Surface and cloud-top temperature are prescribed to be 300 and $200 \mathrm{~K}$, respectively, while surface infrared emissivity and reflectivity are set to be 1.0 and 0.0 , respectively, to represent the thermal infrared radiation features over the tropical ocean. Two experiments have been carried out. The same habit distribu- 

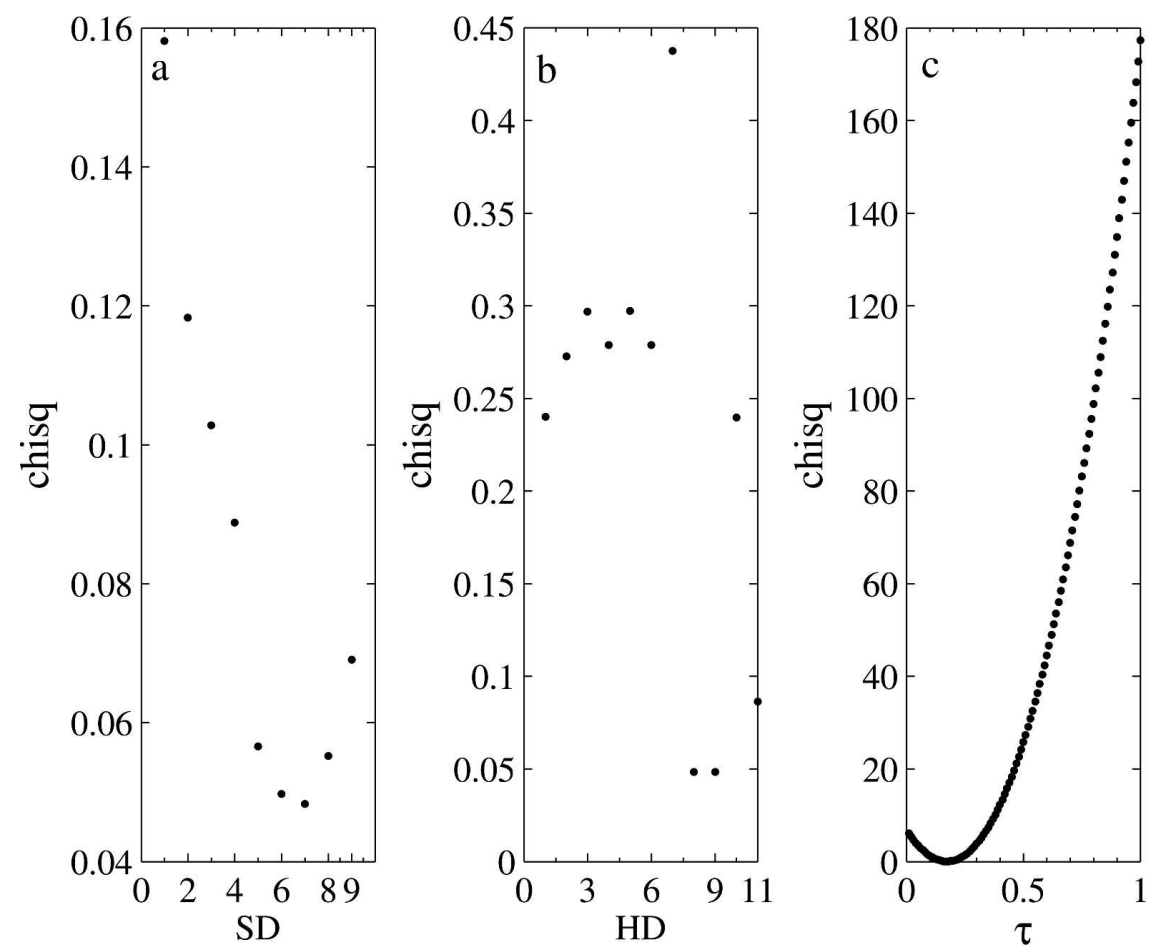

FIG. 2. Chi square $\left(\chi^{2}\right)$ as a function of (a) SD, (b) HD, and (c) cloud visible optical depth $(\tau)$.

tion (HD11) and different size distributions $\left(D_{e}=42 \mu \mathrm{m}\right.$ for CEPEX02 and $D_{e}=80 \mu \mathrm{m}$ for CEPEX03) were used in the first experiment, while in the second experiment, the size distribution was fixed (CEPEX05) and different habit distributions $\left(D_{e}=15 \mu \mathrm{m}\right.$ for HD7 and $D_{e}=28 \mu \mathrm{m}$ for HD9) were used.

Differences of the BT spectra are due to the different radiative properties of ice clouds associated with various combinations of HDs and SDs. Figure 3 shows the bulk extinction efficiency and single-scattering albedo for the four HD-SD combinations that were used in the two experiments within the spectral range 750-1150 $\mathrm{cm}^{-1}$. The bulk extinction efficiency and singlescattering albedo strongly depend on wavenumber in both experiments; however they are less dependent on the mean effective ice crystal size in the first experiment than those in the second.

Figure 4 shows the subband BT spectra simulated in the first experiment for ice clouds with optical depths of 0.1 (left panel), 0.5 (middle panel), and 1.0 (right panel). Clear BT spectra are also shown in each panel by the solid curves with squares for comparison with thin cirrus cloudy spectra. The spectra are displayed in terms of mean BTs for the 14 subbands introduced in section 3c. Between 800 and $960 \mathrm{~cm}^{-1}$, the slope of the mean subband BTs, defined as $\Delta \mathrm{BT} / \Delta \nu$, increases with decreasing mean effective size. Between 1050 and $1130 \mathrm{~cm}^{-1}$, BTs decrease by more than $10 \mathrm{~K}$ as optical depth increases from 0.1 to 1.0. Compared to the BT spectra between 1050 and $1130 \mathrm{~cm}^{-1}$, the spectra between 800 and $960 \mathrm{~cm}^{-1}$ show a stronger sensitivity to wavenumber. Also, the sensitivity of the BT slope to the mean effective size is larger. These results are in agreement with the findings reported by Huang et al. (2004) and Wei et al. (2004). The left panel shows that even for the cirrus optical depth as small as 0.1, the BT difference between cirrus and clear can be as large as $3 \mathrm{~K}$. This sensitivity forms the basis for the retrieval of thin cirrus optical depth using the thermal infrared spectra.

In the second experiment, we used the same SD (CEPEX05) but varying HD. The results are shown in Fig. 5. Although different mean effective sizes $\left(D_{e}=15\right.$ $\mu \mathrm{m}$ for HD7 and $D_{e}=28 \mu \mathrm{m}$ for HD9) are produced, BT slopes over $800-960 \mathrm{~cm}^{-1}$ show a small variation despite the fact that different mean effective sizes are used. We also find that colder BTs are associated with larger mean effective sizes. The BT differences between the two spectra using different HDs can be 1, 5, and more than $10 \mathrm{~K}$ corresponding to the cirrus optical depths of $0.1,0.5$, and 1.0 , respectively. It appears evident that both HD and SD are important in determin- 

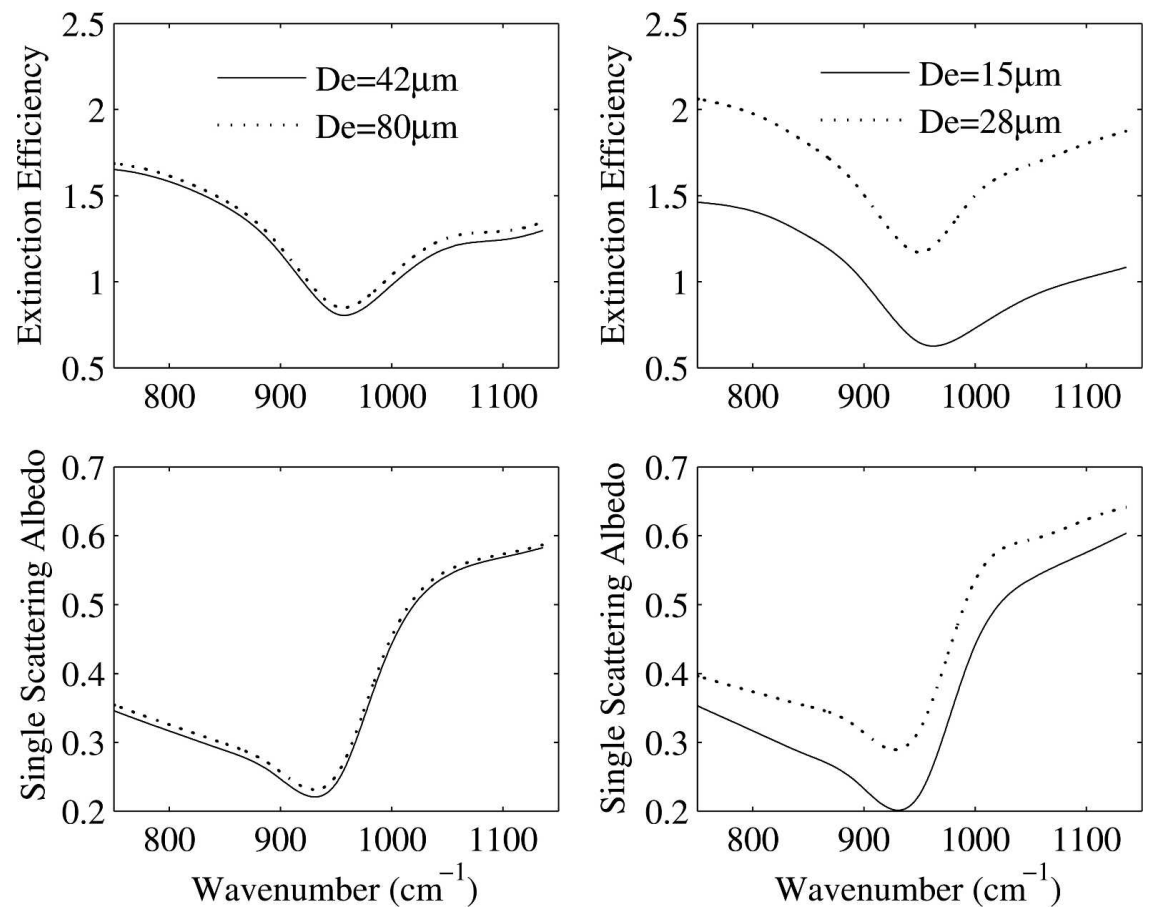

FIG. 3. (left) Bulk extinction efficiency $\left\langle Q_{\text {ext }}(\nu)\right\rangle$ and (right) single-scattering albedo $\langle\omega(\nu)\rangle$ computed from a combination of size and habit distributions in two sensitivity experiments. (left) First and (right) second experiment. The same habit distribution (HD11) and different size distributions $\left(D_{e}=42 \mu \mathrm{m}\right.$ for CEPEX02 and $D_{e}=80 \mu \mathrm{m}$ for CEPEX03) were used in the first experiment, while in the second experiment the size distribution was fixed (CEPEX05) and different habit distributions $\left(D_{e}=15 \mu \mathrm{m}\right.$ for HD7 and $D_{e}=28 \mu \mathrm{m}$ for HD9) were used.

ing the ice cloud bulk radiative properties and in defining the shape of the BT spectra.

\section{b. Interpretation of the AIRS clear and cloudy spectra over the ARM TWP site}

The AIRS is a grating spectrometer on board the NASA's Аqua satellite, launched on 4 May 2002. It covers a spectral region from 3.7 to $15.4 \mu \mathrm{m}$ and has 2378 channels with a nominal spectral resolution of $\lambda / \Delta \lambda=1200$. The nadir spatial resolution is $13.5 \mathrm{~km}$ from the nominal $705-\mathrm{km}$ orbital height. It views the ground through a cross-track rotary scan mirror that provides a $\pm 49.5^{\circ}$ ground coverage every 2.67 -s scan cycle. A total of 90 ground footprints containing all 2378 spectral samples are observed in each cycle. According to the prelaunch testing of AIRS, the absolute radiometric accuracy is $0.2 \mathrm{~K}$ (Pagano et al. 2003).

We applied the methodology developed in this paper to three nighttime AIRS granules; one is clear and the other two contain thin cirrus. An AIRS data granule contains the data gathered in $6 \mathrm{~min}$ for an area of about $2400 \mathrm{~km}$ by $2400 \mathrm{~km}$. We selected granule 158 (28 May 2003, clear), granule 159 (20 June 2003, thin cirrus), and granule 147 (1 March 2005, thin cirrus). All the granules are over the ARM TWP sites and adjacent oceans, among which the first two are over the site at the Manus Island $\left(2.006^{\circ} \mathrm{S}, 147.425^{\circ} \mathrm{E}\right)$ and the last one is over the Nauru Island $\left(0.521^{\circ} \mathrm{S}, 166.916^{\circ} \mathrm{E}\right)$, ideal for comparison with independent ARM measurements. In the cloud-screening method developed by Aumann et al. (2004), a spectral cloud filter was combined with a spatial coherence filter to yield cloud-free spectra with an accuracy of $0.2 \mathrm{~K}$, the same as the AIRS prelaunch radiometric accuracy. Only $1 \%-2 \%$ of the AIRS data passed this test. The clear granule was selected based on this approach, which indicated that clear pixels appeared in this granule. Further, for identification of thin cirrus we follow the detection scheme developed by Kahn et al. (2005), in which the 3.8- and 10.4- $\mu \mathrm{m}$ BT differences were used along with the total column precipitable water measurements. The collocated and coincident browse images obtained by the Moderate Resolution Imaging Spectroradiometer (MODIS) were used to provide a supplementary reference to the cloudy conditions in the selected granule.

Because of the large variation of the cloud properties 

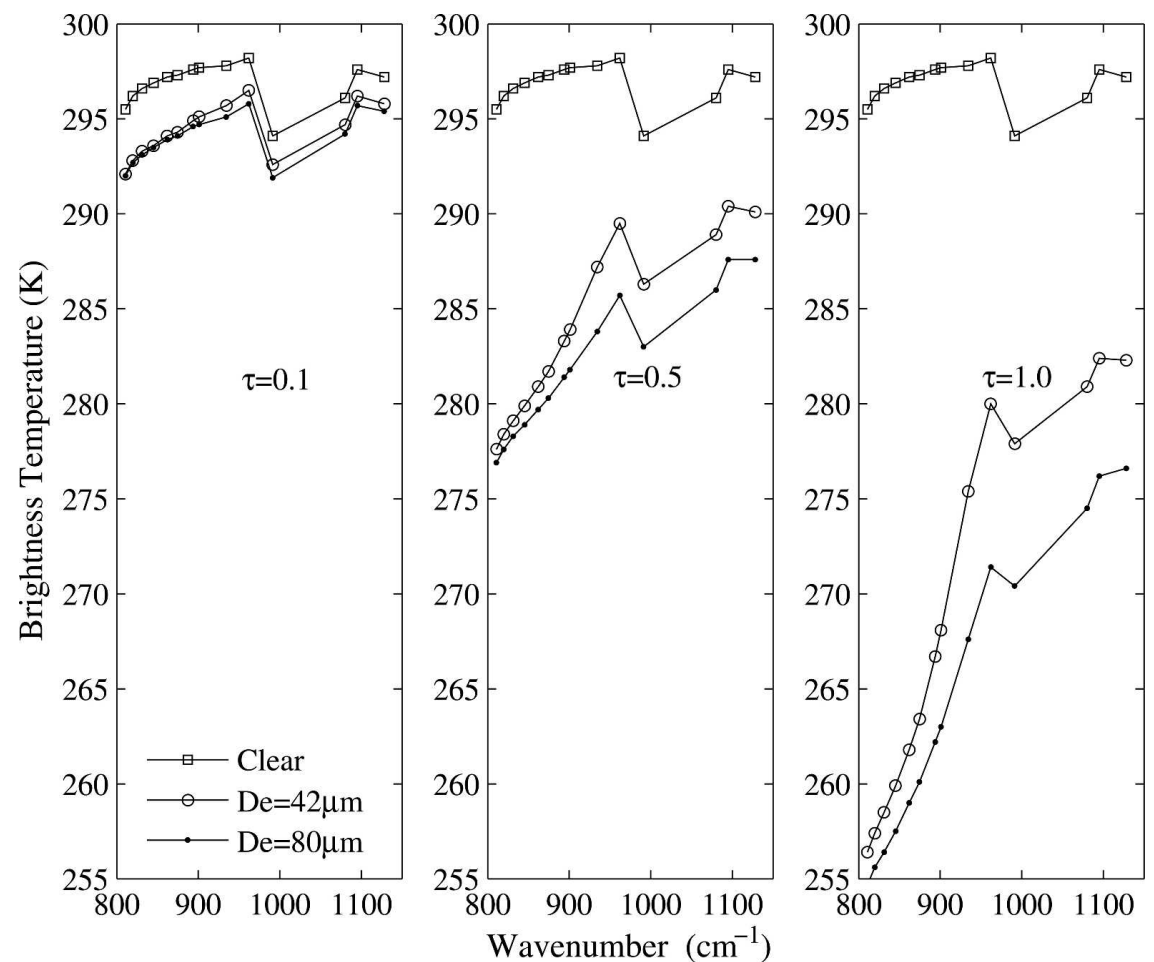

FIG. 4. Sensitivity of the subband BT spectra to variation in optical depth and mean effective size: $\tau=$ (left) 0.1 , (middle) 0.5 , and (right) 1.0. A fixed habit distribution (HD11) and different size distributions $\left(D_{e}=42 \mu \mathrm{m}\right.$ for CEPEX02 and $D_{e}=80 \mu \mathrm{m}$ for CEPEX03) in the standard tropical atmosphere were used in the calculation. Surface and cloud temperature were set to be 300 and $200 \mathrm{~K}$, respectively. Clear-sky BT spectrum is also shown in each panel by solid curve with squares to compare with the cloudy spectra.

in an AIRS granule, we selected a domain inside the granule based on the coincident MODIS browse images. For the 28 May 2003 case, the domain covers an area over $1.5^{\circ} \mathrm{S}-2.5^{\circ} \mathrm{S}$ and $147^{\circ} \mathrm{E}-148^{\circ} \mathrm{E}$. Within this area, five AIRS pixels are considered "clear" according to the detection schemes described above. Figure 6 shows the average residuals between the AIRSobserved and model-simulated BT spectra for the five clear pixels for the individual AIRS channels as well as averaged over the subbands. The zero points indicate the AIRS observations were missing. For the 9.6- $\mu \mathrm{m}$ ozone band, the comparison is less satisfactory. A similar pattern is displayed in the residual analysis of the five AIRS pixels (bottom panel). The averaged (AIRSobserved BTs minus model calculation) differences (averaged over five pixels) indicate that, except for the 9.6- $\mu \mathrm{m}$ ozone band, differences between computed results and observed data are generally less than $1 \mathrm{~K}$, with the AIRS BTs being colder. The colder bias in the AIRS observation may indicate the potential contamination by thin cirrus clouds in the selected scene. For channels in the subbands, the BT differences between the AIRS observation and model results are within $-0.5 \mathrm{~K}$, except for the band at $850 \mathrm{~cm}^{-1}$, which has a value of about $-1.0 \mathrm{~K}$. The reason for discrepancy in the ozone band could be related to uncertainty of the ozone profile in the AIRS data product.

To simulate BTs corresponding to the thin cirrus AIRS granule on 20 June 2003, we have selected an area covering the region $1.0^{\circ} \mathrm{S}-3.0^{\circ} \mathrm{S}$ and $147.0^{\circ} \mathrm{E}-149.0^{\circ} \mathrm{E}$ that contains 15 pixels; the results are shown in Fig. 7. In the first pixel (upper left), the cirrus has a visible optical depth of 0.16 and a mean effective size of $81 \mu \mathrm{m}$, a result of a combination of the CEPEX08 SD and the HD with $100 \%$ hexagonal columns (HD11). Curves in upper right demonstrate another pixel for a cloud with a visible optical depth of 0.20 and a mean effective size of $78 \mu \mathrm{m}$ having a different HD (HD9). The average residuals (AIRS minus model) for the 15 thin cirrus cloudy pixels are shown in the lower panel. Similar to the clear case, residuals are within $0.5 \mathrm{~K}$ in the subbands between 800 and $960 \mathrm{~cm}^{-1}$ region, while the largest residuals occur in the ozone band. Differences in the $1050-1130 \mathrm{~cm}^{-1}$ region are larger but still within $-1 \mathrm{~K}$ 

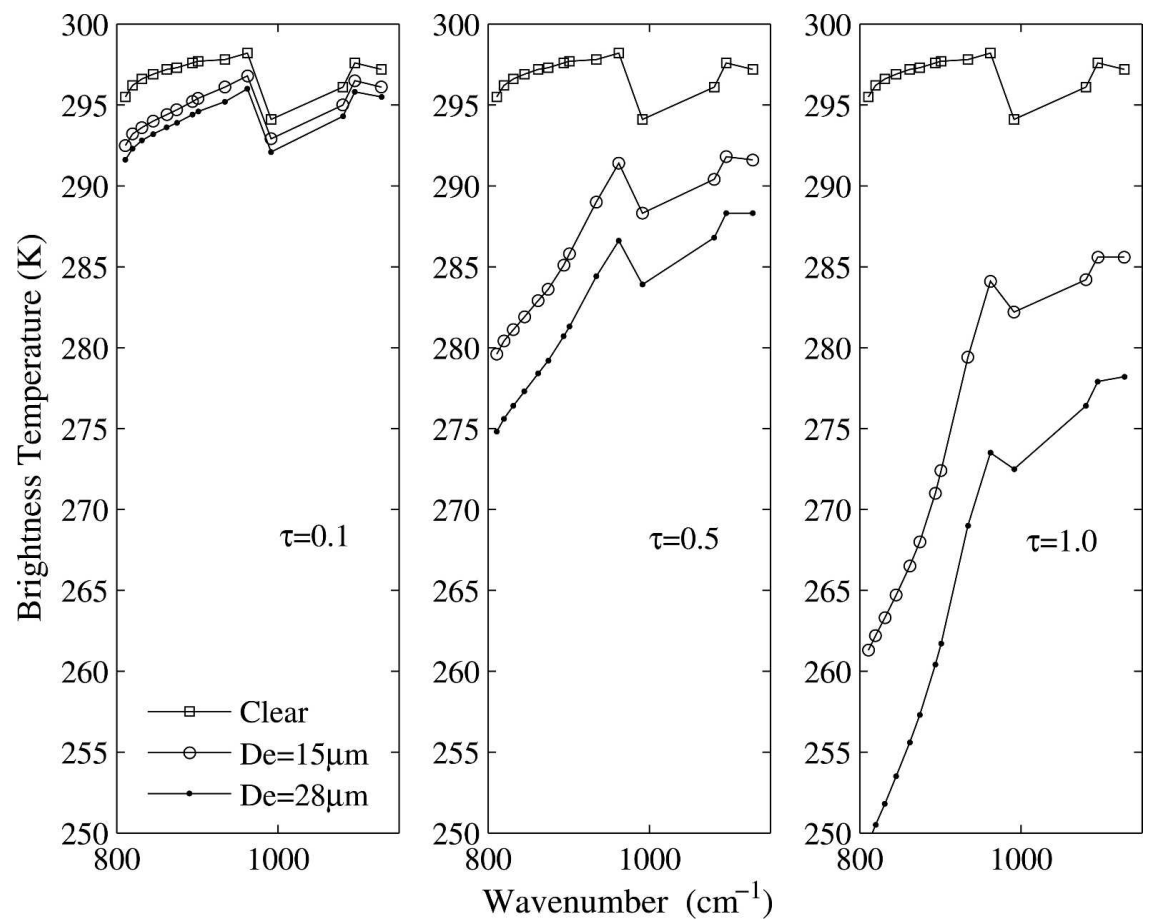

FIG. 5. Same as in Fig. 4, except that a fixed size distribution (CEPEX05) and different habit distributions $\left(D_{e}=15 \mu \mathrm{m}\right.$ for HD7 and $D_{e}=28 \mu \mathrm{m}$ for HD9) were used in the calculation.

for the subband channels. The AIRS cirrus BTs are warmer than the model results. It is possible that the neglect of multiple scattering may contribute to the bias in this model calculation.

In granule 159 (20 June 2003) the selected 15 pixels

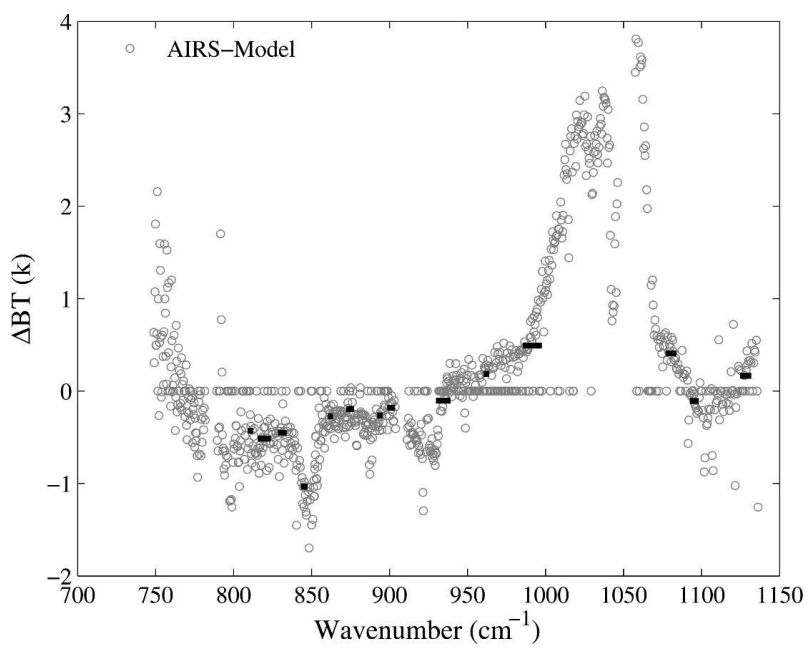

FIG. 6. The average residuals (AIRS - Model) correspond to all clear simulations. Gray circles are residuals for each AIRS channel. The black horizontal bars show the mean average residuals over the 14 subbands indicated by the widths of the bars. were all thin cirrus cases with the AIRS-inferred optical depths less than 0.3, while granule 147 (1 March 2005) contains optically thicker cirrus clouds. The domain selected around the Nauru Island site covers the region $0^{\circ}-1.5^{\circ} \mathrm{S}$ and $165^{\circ}-167.5^{\circ} \mathrm{E}$ and contains 14 AIRS pixels, 7 of which have the AIRS-inferred optical depths smaller than 0.3 and their simulation results (not shown) are similar to those for granule 159 in Fig. 7. However, there are three thicker cirrus pixels with residuals larger than $1 \mathrm{~K}$ in the subbands that have optical depths of $0.69,0.4$, and 0.32 , respectively. This suggests that multiple-scattering contributions become important as cirrus optical depth becomes larger than 0.3, which is the upper limit for application of the current radiative transfer model.

Based on the AIRS validation studies discussed in section $3 b$, we have carried out different numerical experiments for the case on 20 June 2003 to study the effects of input parameter uncertainty and instrument noise on the retrieval accuracy. The AIRS BT spectra, temperature profile, water vapor profile, cloud-top temperature, ozone profiles, and surface temperature have been perturbed by $\pm 0.2 \mathrm{~K}, \pm 1.0 \mathrm{~K}, \pm 15 \%$, $\pm 6.5 \mathrm{~K}, \pm 20 \%$, and $\pm 1.0 \mathrm{~K}$, respectively. These are bias values and not standard deviations. Results show that uncertainties in the water vapor profile are the 
$(-1.48,148.91)$
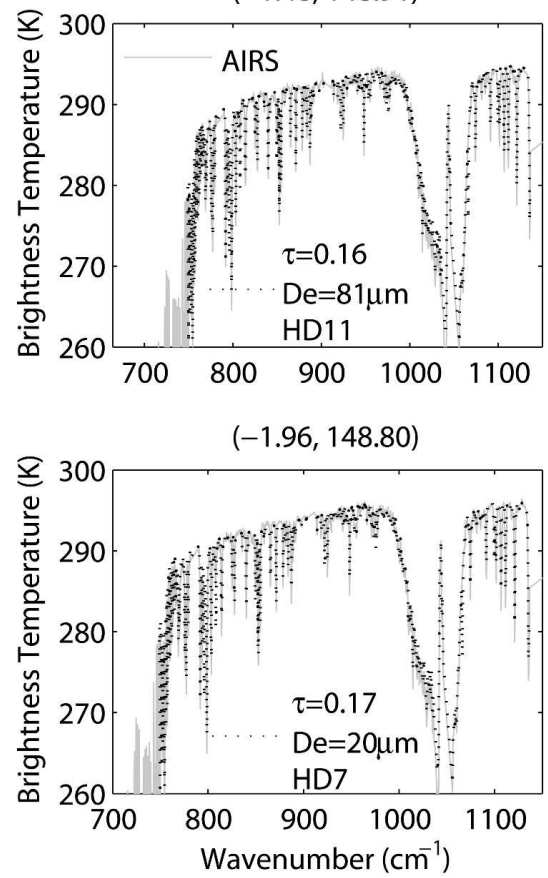

$(-1.25,147.23)$
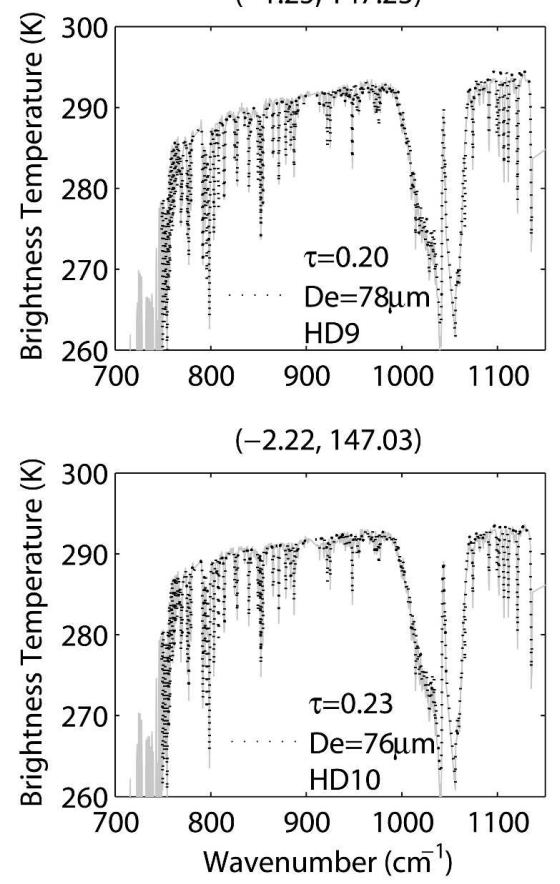

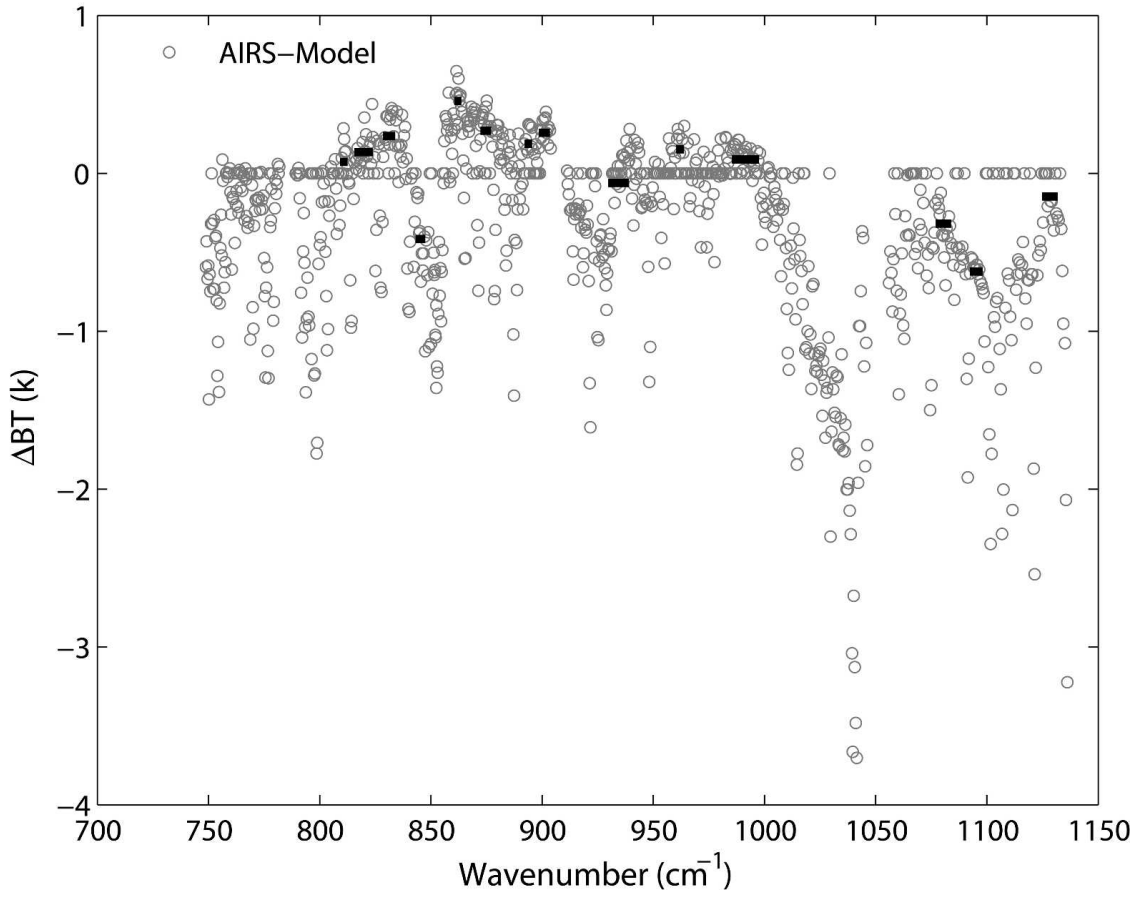

FIG. 7. (top) Four AIRS thin cirrus cloudy BT spectra calculated from simulation and observation in the $750-1130 \mathrm{~cm}^{-1}$ region. The cloud properties were determined by the minimization method. (bottom) The average residuals (AIRS - Model) corresponding to all thin cirrus cases. Gray circles are residuals for each AIRS channel. The black horizontal bars show the mean average residuals over the 14 subbands indicated by the widths of the bars. 
major error source, which causes an error in optical depth less than 0.05. Errors in the effective particle diameter on average are less than $8 \mu \mathrm{m}$.

\section{c. Validation using ARM TWP data}

To have an independent check on the model results, we compare the optimal mean effective ice crystal size and optical depth to those determined from the MMCR retrieval developed by Mace et al. (2002). The extinction coefficient can be calculated by using the following equations ( $\mathrm{Fu}$ and Liou 1993):

$$
\begin{aligned}
\beta_{\mathrm{ext}} & =\operatorname{IWC}\left(c+d / D_{e}\right), \\
\tau & =\beta_{\mathrm{ext}} \Delta z,
\end{aligned}
$$

where IWC and $D_{e}$ denote the IWC and mean effective size retrieved from the MMCR data, respectively; $\beta_{\text {ext }}$ is the IR extinction coefficient; $\Delta z$ is the cloud thickness obtained from the MMCR retrieval; and $c$ and $d$ are constants. For columns, $c \approx-6.656 \times 10^{-3}$ and $d \approx$ 3.686 (Fu and Liou 1993). Based on these parameterization equations, optical depth can be computed as a function of time and altitude.

To validate the calculations for the two cirrus granules, we used the mean wind of the cloud layer on the basis of the nearest wind-sounding profile in the collocation method, and converted the MMCR retrieval results from time domain to spatial domain to compare with satellite measurements. This assumes that the wind speed and direction remained the same during the time period between the AIRS overpass of ARM sites and the collocation times of different pixels. Among the 29 thin cirrus cloudy pixels reported in this paper, only those along the wind direction could be collocated with the ground-based measurements. Cirrus parameters were assumed to remain unchanged during the collocation time period. If a pixel is too far away from ARM sites, then the collocation time of this pixel would be far apart from the AIRS overpass, and collocation and comparison of this AIRS pixel and the MMCR time series would not be considered "true collocation" for validation. Since AIRS have a nadir spatial resolution of $13.5 \mathrm{~km}$ (Pagano et al. 2003), and the wind speed at the cirrus layers was very small $\left(5 \mathrm{~m} \mathrm{~s}^{-1}\right.$ on 20 July 2003 and $10 \mathrm{~m} \mathrm{~s}^{-1}$ on 1 March 2005), it took about $1 \mathrm{hr}$ for clouds in one pixel to drift to the adjacent pixel. A 1-hr average was taken for the ground-based measurements.

Given the criteria of the collocation method, only four pixels were considered as "true collocation" for this comparison in the granule 159 from 20 June 2003 (pixels 14, 10, 8, and 4). As shown in the Table 3, the AIRS-inferred optical depth is slightly larger than the MMCR retrieval value, while the AIRS-inferred mean
TABLE 3. Comparison of the cloud properties inferred from AIRS data and MMCR retrieval for AIRS granule 2003.06.20.159.

\begin{tabular}{cccccc}
\hline \hline \multicolumn{2}{c}{ Pixels } & 4 & 8 & 10 & 14 \\
\hline$\tau$ & MMCR & 0.07 & 0.03 & 0.13 & $\sim 0$ \\
& AIRS & 0.2 & 0.09 & 0.26 & 0.01 \\
$D_{e}(\mu \mathrm{m})$ & MMCR & 81 & 87 & 106 & $\sim 0$ \\
& AIRS & 78 & 67 & 91.5 & 19.6 \\
\hline
\end{tabular}

effective size is smaller than the MMCR retrieval result. This discrepancy could be explained by the fact that MMCR generally misses small particles (Comstock et al. 2002). We note that for pixel 14, MMCR completely missed the thin cirrus layer, with $\tau$ and $D_{e}$ approximately equal to zero. However, the AIRS-inferred result shows that a thin cloud was present having a $D_{e}$ of $19.6 \mu \mathrm{m}$ and a $\tau$ of 0.01 . This may be due to MMCR's missing small ice crystals, but may also be due in part to our analysis and the possible spatial and temporal variations in cirrus.

Applying the aforementioned criteria of collocation to the 11 pixels (granule 147, 1 March 2005) with the condition that the simulated BT spectra closely agree with AIRS-measured spectra, four pixels have been selected for comparison $(6,9,10$, and 13), as shown by Table 4. The AIRS-inferred and MMCR-retrieved optical depths for these four pixels are from 0.05 to 0.37 and from 0 to 0.18 , respectively. The effective particle sizes range from 20 to $91.5 \mu \mathrm{m}$ and 0 to $72 \mu \mathrm{m}$ based on the AIRS and MMCR retrievals, respectively. Pixel 6 collocated with a thin cirrus layer between 17 and 18 $\mathrm{km}$ that occurred $4 \mathrm{hr}$ earlier than the AIRS overpass at the Nauru Island on that day. This thin cirrus layer was missed by the MMCR detection and only captured by the simultaneous MPL measurements. For this reason, the results of MMCR retrievals in this pixel are $\sim 0$ for both optical depth and particle size. As expected, for pixels 9 and 13, the AIRS-inferred optical depths (mean effective sizes) are larger (smaller) than the MMCR retrieval values. However, exception was found

TABLE 4. Comparison of the cloud properties inferred from AIRS data, MMCR, and MPL retrievals for AIRS granule 2005.03.01.147. Note that for pixel 6, there is no MMCR reflectivity data, and for pixels 10 and 13 , there is no MPL backscattering signal.

\begin{tabular}{llcccc}
\hline \hline \multicolumn{2}{c}{ Pixels } & 6 & 9 & 10 & 13 \\
\hline$\tau$ & MMCR & - & 0.10 & 0.18 & 0.09 \\
& MPL & 0.02 & 0.15 & - & - \\
& AIRS & 0.05 & 0.13 & 0.37 & 0.11 \\
$D_{e}(\mu \mathrm{m})$ & MMCR & - & 63 & 72 & 57 \\
& AIRS & 20 & 29 & 91.5 & 20
\end{tabular}


for the mean effective size of pixel 10, in which the AIRS-inferred optical depth is 0.37. Although good agreement between the calculated and AIRS-measured BTs has also been obtained for this pixel, the cirrus clouds with optical depths larger than the 0.3 threshold may be in error because of the neglect of multiple scattering in retrieval analysis.

Although the normalized MPL backscatter profiles with all known instrument artifacts removed was not made available for this case study, we have made a preliminary comparison with the MPL retrieval based on raw data. Because pixels 10 and 13 contain thicker cirrus, MPL did not have backscattering signals at the collocated times. Therefore, comparisons with MPL were made only for pixels 6 and 9 where the MPLretrieved optical depths are 0.02 and 0.15 , respectively (J. M. Comstock 2005, personal communication).

\section{Summary}

In this study, we have developed a fast radiative transfer model for the interpretation of AIRS data by combining the OPTRAN model with a thin cirrus parameterization. This effort includes the construction of size and habit distribution models for cirrus clouds and the calculation of their bulk optical properties. As a demonstration, we analyze 5 clear pixels and 29 thin cirrus cloudy pixels in three AIRS data granules coincident with the ARM program sites at Manus Island and Nauru Island in the tropical western Pacific. In the clear cases, differences between the AIRS-observed spectral BTs and the modeled results are within -0.5 to $-1 \mathrm{~K}$ for the subband average at $800-1130 \mathrm{~cm}^{-1}$. In the thin cirrus case, we find that differences in the subbands channels are within +0.5 to $-1 \mathrm{~K}$. Relatively larger differences on the order of 4-5 K occur in some absorption lines, including those in the ozone 9.6- $\mu \mathrm{m}$ band region for both clear and cloudy cases. These differences may be related to uncertainties in the atmospheric state, which is taken from the AIRS level 2 operational support product.

We have also developed a $\chi^{2}$-minimization method to infer the optical depth and mean effective ice crystal size in thin cirrus conditions. We show that the AIRSinferred optical depth and mean effective size are consistent with the results independently determined from the collocated and coincident MMCR measurements available at the ARM TWP Manus Island and Nauru Island sites for the cases selected.

Finally, we have investigated the sensitivity of the spectral BT to cirrus optical depth and ice crystal size and habit. Cirrus cloudy radiances in the 800-1130$\mathrm{cm}^{-1}$ window are shown to be sensitive to all three parameters. The degree of their sensitivity varies spectrally, suggesting that it appears feasible to use BT spectra to infer them simultaneously. Sufficient sensitivity of the ice crystal habit in the thermal infrared spectrum illustrated in our analysis appears to be a new finding. Additional data analysis is required to determine the different roles of ice crystal size and habit in shaping the AIRS spectra. In the present theoretical modeling for fast radiance calculations in thin cirrus conditions, the effect of multiple scattering of thermal emission has not been accounted for. For cirrus clouds with optical depths larger than about 0.3, multiple scattering may become significant, an area requiring further investigation. The errors in the computation caused by uncertainties in AIRS-measured BT spectra, atmospheric profiles, and surface and cloud temperature have been studied and they are relatively small compared with the sensitivity of thermal infrared spectrum to optical depth. Last, updated SD and HD models that can realistically represent the tropical and midlatitude cirrus cloud conditions should be constructed in future remote sensing studies.

Acknowledgments. We thank Annmarie Eldering for suggesting further examination of applying the $\chi^{2}$ minimization method to AIRS radiances, and Jennifer M. Comstock for providing MPL raw data retrieval. This research has been supported by DOE Grant DEFG03-00ER62904 and NOAA Grant NA03NES4400011.

\section{REFERENCES}

Aumann, H. H., and Coauthors, 2003: AIRS/AMSU/HSB on the Aqua mission: Design, science objectives, data products, and processing systems. IEEE Trans. Geosci. Remote Sens., 41, 253-264.

— D. Gregorich, and D. Barron, 2004: Spectral cloud-filtering of AIRS data: Non-polar ocean. Proc. SPIE, 5548, 313-320.

Baum, B. A., A. J. Heymsfield, P. Yang, and S. M. Thomas, 2005: Bulk scattering properties for the remote sensing of ice clouds. Part I: Microphysical data and models. J. Appl. Meteor., 44, 1885-1895.

Chahine, M. T., and Coauthors, 2006: AIRS: Improving weather forecasting and providing new data on greenhouse gases. Bull. Amer. Meteor. Soc., 87, 911-926.

Clough, S. A., M. J. Iacono, and J.-L. Moncet, 1992: Line-by-line calculations of atmospheric fluxes and cooling rates: Application to water vapor. J. Geophys. Res., 97, 15 761-15 785.

Comstock, J. M., T. P. Ackerman, and G. G. Mace, 2002: Groundbased lidar and radar remote sensing of tropical cirrus clouds at Nauru Island: Cloud statistics and radiative impacts. $J$. Geophys. Res., 107, 4714, doi:10.1029/2002JD002203.

DeSlover, D. H., W. H. Smith, P. Piironen, and E. W. Eloranta, 1999: A methodology for measuring cirrus cloud visible to infrared spectral optical depth ratios. J. Atmos. Oceanic Technol., 16, 251-262.

Divakarla, M., C. Barnet, M. D. Goldberg, L. McMillin, E. S. 
Maddy, W. W. Wolf, L. Zhou, and X. Liu, 2006: Validation of Atmospheric Infrared Sounder temperature and water vapor retrievals with matched radiosonde measurements and forecasts. J. Geophys. Res., 111, D09S15, doi:10.1029/ 2005JD006116.

Fetzer, E. J., 2006: Preface to special section: Validation of Atmospheric Infrared Sounder observations. J. Geophys. Res., 111, D09S01, doi:10.1029/2005JD007020.

Fleming, H. E., and L. M. McMillin, 1977: Atmospheric transmittance of an absorbing gas. 2: A computationally fast and accurate transmittance model for slant paths at different zenith angles. Appl. Opt., 16, 1366-1370.

Foot, J. S., 1988: Some observations of the optical properties of clouds. Part II: Cirrus. Quart. J. Roy. Meteor. Soc., 114, 145164.

Francis, P. N., A. Jones, R. W. Saunders, K. P. Shine, A. Slingo, and Z. Sun, 1994: An observational and theoretical study of the radiative properties of cirrus: Some results from ICE'89. Quart. J. Roy. Meteor. Soc., 120, 809-848.

Fu, Q., and K. N. Liou, 1993: Parameterization of the radiative properties of cirrus clouds. J. Atmos. Sci., 50, 2008-2025.

Huang, H.-L., P. Yang, H. Wei, B. A. Baum, Y.-X. Hu, P. Antonelli, and S. A. Ackerman, 2004: Inference of ice cloud properties from high-spectral resolution infrared observations. IEEE Trans. Geosci. Remote Sens., 42, 842-852.

Kahn, B. H., and Coauthors, 2005: Nighttime cirrus detection using Atmospheric Infrared Sounder window channels and total column water vapor. J. Geophys. Res., 110, D07203, doi:10.1029/2004JD005430.

— , A. Eldering, A. J. Braverman, E. J. Fetzer, E. Fishbein, J. H. Jiang, and D. Wu, 2007: Towards characterization of upper tropospheric clouds using Atmospheric Infrared Sounder and Microwave Limb Sounder observations. J. Geophys. Res., 112, D05202, doi:10.1029/2006JD007336.

Kleespies, T. J., P. van Delst, L. M. McMillin, and J. Derber, 2004: Atmospheric transmittance of an absorbing gas. 6. OPTRAN status report and introduction to the NESDIS/NCEP community radiative transfer model. Appl. Opt., 43, 3103-3109.

Liou, K. N., 1986: Influence of cirrus clouds on weather and climate processes: A global perspective. Mon. Wea. Rev., 114, 1167-1199.

Mace, G. G., A. J. Heymsfield, and M. R. Poellot, 2002: On retrieving the microphysical properties of cirrus clouds using the moments of the millimeter-wavelength Doppler spectrum. J. Geophys. Res., 107, 4851, doi:10.1029/2001JD001308.

Macke, A., J. Mueller, and E. Raschke, 1996: Single scattering properties of atmospheric ice crystals. J. Atmos. Sci., 53, 2813-2825.

McClatchey, R. A., R. W. Fenn, J. E. A. Selby, P. E. Volz, and J. S. Garing, 1972: Optical properties of the atmosphere. 3d ed. Environmental Research Papers 411, AFCRL-72-0497, Air Force Cambridge Research Papers, 103 pp.

McFarquhar, G. M., and A. J. Heymsfield, 1996: Microphysical characteristics of three anvils sampled during the Central Equatorial Pacific Experiment. J. Atmos. Sci., 53, 2401-2423. - and _ 1997: Parameterization of tropical cirrus ice crystal size distributions and implications for radiative transfer: Results from CEPEX. J. Atmos. Sci., 54, 2187-2200.

, —_, A. Macke, J. Iaquinta, and S. M. Aulenbach, 1999: Use of observed ice crystal sizes and shapes to calculate meanscattering properties and multispectral radiances: CEPEX April 4, 1993, case study. J. Geophys. Res., 104, $31763-$ 31779.
McMillin, L. M., and H. E. Fleming, 1976: Atmospheric transmittance of an absorbing gas: A computationally fast and accurate transmittance model for absorbing gases with constant mixing ratios in inhomogeneous atmospheres. Appl. Opt., 15, 358-363.

,-- , and M. L. Hill, 1979: Atmospheric transmittance of an absorbing gas. 3: A computationally fast and accurate transmittance model for absorbing gases with variable mixing ratios. Appl. Opt., 18, 1600-1606.

- L. J. Crone, M. D. Goldberg, and T. J. Kleespies, 1995a: Atmospheric transmittance of an absorbing gas. 4. OPTRAN: A computationally fast and accurate transmittance model for absorbing gases with variable mixing ratios at variable viewing angles. Appl. Opt., 34, 6269-6274.

,$- \ldots$, and T. J. Kleespies, 1995b: Atmospheric transmittance of an absorbing gas. 5. Improvements to the OPTRAN approach. Appl. Opt., 34, 8396-8399.

Minnis, P., D. P. Garber, D. F. Young, R. F. Arduini, and Y. Takano, 1998: Parameterizations of reflectance and effective emittance for satellite remote sensing of cloud properties. $J$. Atmos. Sci., 55, 3313-3339.

Olsen, E. T., Ed., cited 2003: AIRS Version 3.0 L2 data release documentation. [Available online at http://daac.gsfc.nasa. gov/AIRS/documentation/airs_12/V3.0_L2_Data_Release_ UG.pdf.]

— Ed., cited 2005: AIRS/AMSU/HSB Version 4 data release user guide. [Available online at http://daac.gsfc.nasa.gov/ AIRS/documentation/v4_docs/V4_Data_Release_UG.pdf.]

Ou, S. C., K. N. Liou, W. M. Gooch, and Y. Takano, 1993: Remote sensing of cirrus cloud parameters using AVHRR 3.7 and $10.9 \mu \mathrm{m}$ channels. Appl. Opt., 32, 2171-2180.

Pagano, T. S., H. H. Aumann, D. E. Hagan, and K. Overoye, 2003: Prelaunch and in-flight radiometric calibration of the Atmospheric Infrared Sounder (AIRS). IEEE Trans. Geosci. Remote Sens., 41, 265-273.

Rolland, P., K. N. Liou, M. D. King, S.-C. Tsay, and G. M. McFarquhar, 2000: Remote sensing of optical and microphysical properties of cirrus clouds using moderate-resolution imaging spectroradiometer channels: Methodology and sensitivity to physical assumptions. J. Geophys. Res., 105, 11 721-11 738.

Saunders, R., 2000: A global comparison of HIRS and AVHRR radiances. Proc. 11th Int. ATOVS Study Conf., Budapest, Hungary, BMRC, 345 pp.

Strow, L., S. E. Hannon, S. De Souza-Machado, H. E. Motteler, and D. Tobin, 2003: An overview of the AIRS radiative transfer model. IEEE Trans. Geosci. Remote Sens., 41, 303313

Tobin, D.C., and Coauthors, 2006: Radiometric and spectral validation of Atmospheric Infrared Sounder observations with the aircraft-based Scanning High-Resolution Interferometer Sounder. J. Geophys. Res., 111, D09S02, doi:10.1029/ 2005JD006094.

Wang, P. H., M. P. McCormick, P. Minnis, G. S. Kent, and K. M. Skeens, 1996: A 6-year climatology of cloud occurrence frequency from SAGE II observations (1985-1990). J. Geophys. Res., 101, 29 407-29 429.

Wei, H., P. Yang, J. Li, B. A. Baum, H.-L. Huang, S. Platnick, Y.-X. Hu, and L. Strow, 2004: Retrieval of ice cloud optical thickness from Atmospheric Infrared Sounder (AIRS) measurements. IEEE Trans. Geosci. Remote Sens., 42, 2254-2265.

Wylie, D. P., and W. P. Menzel, 1999: Eight years of high cloud statistics using HIRS. J. Climate, 12, 170-184.

— D. L. Jackson, W. P. Menzel, and J. J. Bates, 2005: Trends in 
global cloud cover in two decades of HIRS observations. $J$. Climate, 18, 3021-3031.

Wyser, K., and P. Yang, 1998: Average ice crystal size and bulk short-wave single-scattering properties of cirrus clouds. Atmos. Res., 49, 315-335.

Yang, P., K. N. Liou, K. Wyser, and D. Mitchell, 2000: Parameterization of the scattering and absorption properties of individual ice crystals. J. Geophys. Res., 105, 4699-4718.

— B. A. Baum, A. J. Heymsfield, Y.-X. Hu, H.-L. Huang, S.-C. Tsay, and S. A. Ackerman, 2003: Single-scattering properties of droxtals. J. Quant. Spectrosc. Radiat. Transfer, 79-80, 1159-1169.

- , H. Wei, H.-L. Huang, B. A. Baum, Y.-X. Hu, G. W. Kattawar, M. I. Mishchenko, and Q. Fu, 2005: Scattering and absorption property database for nonspherical ice particles in the near- through far-infrared spectral region. Appl. Opt., 44, 5512-5523.

Zhang, Z., P. Yang, G. W. Kattawar, S.-C. Tsay, B. A. Baum, Y.-X. Hu, A. J. Heymsfield, and J. Reichardt, 2004: Geometrical-optics solution to light scattering by droxtal ice crystals. Appl. Opt., 43, 2490-2499. 